FME-17001-HH

Verso: Front. Mech. Eng. 2017

Recto: Hamed HABIBI et al. Power maximization of variable-speed variable-pitch wind turbines

DOI: $10.1007 / \mathrm{s} 11465-017-0431-4$

RESEARCH ARTICLE

Hamed HABIBI, Hamed RAHIMI NOHOOJI, Ian HOWARD

\title{
Power maximization of variable-speed variable-pitch wind turbines using passive adaptive neural fault tolerant control
}

() Higher Education Press and Springer-Verlag Berlin Heidelberg 2017

Received July 12, 2016; accepted January 3, 2017

Hamed HABIBI $(\varangle)$, Hamed RAHIMI NOHOOJI, Ian HOWARD

Department of Science and Engineering, School of Civil and Mechanical Engineering, Curtin University, Perth, Australia

Email: hamed.habibi@ postgrad.curtin.edu.au

\begin{abstract}
Power maximization has always been a practical consideration in wind turbines. The question of how to address optimal power capture, especially when the system dynamics are nonlinear and the actuators are subject to unknown faults, is significant. This paper studies the control methodology for variable-speed variable-pitch wind turbines including the effects of uncertain nonlinear dynamics, system fault uncertainties, and unknown external disturbances. The nonlinear model of the wind turbine is presented, and the problem of maximizing extracted energy is formulated by designing the optimal desired states. With the known system, a model-based nonlinear controller is designed; then, to handle uncertainties, the unknown nonlinearities of the wind turbine are estimated by utilizing radial basis function neural networks. The adaptive neural fault tolerant control is designed passively to be robust on model uncertainties, disturbances including wind speed and model noises, and completely unknown actuator faults including generator torque and pitch actuator torque. The Lyapunov direct method is employed to prove that the closed-loop system is uniformly bounded. Simulation studies are performed to verify the effectiveness of the proposed method.
\end{abstract}

Keywords wind turbine nonlinear model, maximum power tracking, passive fault tolerant control, adaptive neural control

\section{Introduction}

Nowadays wind turbines as an efficient emerging mechanism to harvest energy, are considered as one of the most effective methods to produce power with minimal pollution and environmental damage [1]. On the other hand, the huge costs of wind turbines must be paid off by reasonable production of electrical power [2]. One of the most important procedures to make wind turbines work efficiently is to keep their operation within the desired performance regions. Accordingly, it is very important to utilize proper control schemes to increase the produced power [3,4].

Additionally, as wind turbines are large, expensive and hard-to-maintain structures, the fault diagnosis and isolation (FDI), and fault tolerant control (FTC) concepts can be used to increase the wind turbine reliability [5-8]. These methods can also help the system to avoid vulnerability in dangerous wind situations [7,8]. FTC is a new aspect in wind turbines studies [9]. This method tries to keep wind turbine operating, despite the existence of faults [10]. Two different FTC 
schemes are normally considered, namely active and passive [11]. In active FTC, there should be a fault diagnosis scheme to detect faults, on which basis the controller will be reconfigured to make the wind turbine operate normally. On the other hand, in passive FTC, the nominal controller is initially designed such that it is robust against a range of considered faults. The passive FTC is conservative compared to the active one, but it does not depend on fault detection algorithms which mostly detect faults in wind turbines inaccurately, due to the system nonlinear behaviour [12].

The standard wind turbine control approach focuses on tracking the desired, so-called ideal power curve, as shown in Fig. 1 [13], where $P_{\mathrm{a}}$ is the ideal produced power and $V_{\mathrm{w}}$ is the effective wind speed at the rotor plane.

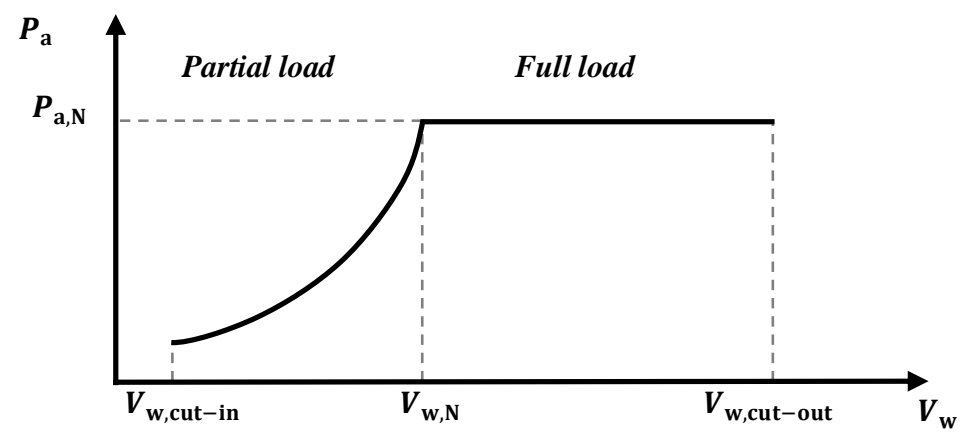

Fig. 1 Ideal power curve [13]

The cut-in wind speed, $V_{\text {w.cutin }}$, is the lowest operational wind speed and the cut-out wind speed, $V_{\mathrm{w}, \text { cut-out }}$ represents the highest operational wind speed for the wind turbine and the wind turbine is shut down for wind speeds out of this range. For the system and control level perspective, there are two different regions where the wind turbine operates. The first region is known as the partial load operation and occurs for wind speeds from $V_{\mathrm{w}, \mathrm{cutin}}$ to the nominal wind speed, $V_{\mathrm{w}, \mathrm{N}}$, which is the lowest wind speed where the turbine produces its nominal power, $P_{\mathrm{a}, \mathrm{N}}$. The full load region is between $V_{\mathrm{w}, \mathrm{N}}$ and $V_{\mathrm{w}, \text { cut-out }}$. In the partial load region, where the focus of this paper is concentrated, it is desirable to extract as much power as possible from the wind, whilst in the full load region, the output power should be kept at its nominal value, $P_{\mathrm{a}, \mathrm{N}}[14]$, to maximize system reliability and to reduce operational costs.

The control of wind turbines can be considered as effectively controlling the electromagnetic torque load on the generator shaft in partial load operation and as controlling the blade pitch angle in full load operation [15]. The main controller scheme in partial load operation is the use of the so-called standard reference controller that excludes the wind speed from the governing equations and derives a formula to keep the power coefficient at its optimal value [16]. On the other hand, to consider the wind speed variation in the control design, in Ref. [17] it was assumed that the wind speed was measurable and accordingly the desired trajectory can be defined. However, since this assumption is rarely true, some studies $[18,19]$ have reported on the design of estimators to measure the effective wind speed or in developing other novel adaptive methods [20].

Due to its aerodynamic and generator components, it is known that the wind turbine systems are highly nonlinear and strongly coupled systems [21]. However, several studies [12,14,22-25] have reported on the control of the linearized model of wind turbine systems. In some papers, where PID control is used, the nonlinear model of the wind turbine system is linearized around some operating points, which are based on wind speeds that lead to a family of linearized models. Therefore, for each of them, a PID controller can be designed and using gain scheduling method, the final control is constructed as switching among these linear controllers. However, because the wind speed can vary abruptly, fast switching may lead to system instability [26]. On the other hand, to guarantee stability and performance, robust linear parameter varying (LVP) methods which, to some degree, are conservative can be deployed [27]. 
Nevertheless, linear model control of wind turbines leads to some model inaccuracies which may decrease the efficiency of the control system. On the other hand, by using nonlinear and robust controllers more accurate results can be obtained [28-30]. However, the development of an accurate dynamic model of real physical wind turbines is not currently available or is extremely hard to formulate [27]. Accordingly, the design of model-based control is a challenging issue for practical wind turbine control systems. Thus, the enhanced control of a wind turbine without apriori knowledge of its dynamics, by employing approximating methods like fuzzy logic [31-33] or neural network [34,35], has attracted much attention.

This paper presents a novel nonlinear modeling and control approach for variable-speed variable-pitch wind turbines operating in the partial load region. The system dynamics are modeled and an optimal desired trajectory is defined in order to maximize the system power. The proposed model-based control is used to prove that the obtained controller guarantees the asymptotically stability of the closed-loop system. Uncertainties in the system are then considered and an adaptive neural network model is proposed to handle the uncertainties. Unknown external disturbances and unknown actuator faults are also applied and a proper algorithm was designed to cope with such difficulties. Simulations are performed to verify the effectiveness of the method. The structure of the paper is organized as follows. In Section 2, the wind turbine nonlinear model is presented. The proposed control strategy to maximize the harvested energy is stated in Section 3, and designed in Section 4. Simulations are performed and results are discussed in Section 5 where two different wind speeds and faults scenarios have been implemented to evaluate the proposed controllers. The conclusion remarks with a summary of the paper are given in Section 6 .

It should be noted that matrices and vectors are represented by uppercase and lowercase with bold face symbols, respectively, and scalars are represented in regular forms.

\section{Dynamic model of wind turbine}

In this section, the nonlinear model of the wind turbine system is described. The control strategy of the wind turbine is then illustrated and consequently, the nonlinear state space representation of the wind turbine model is derived. Finally, the possible faults which are going to be controlled via the proposed controller are pointed out. The wind turbine model can be divided and modelled into the following subsystems [13].

\subsection{Aerodynamic model}

The kinetic energy in the wind can be transferred to mechanical energy via the blades of the wind turbines that are directly connected to the rotor shaft rotating with speed $\omega_{\mathrm{r}}$. The resulting applied rotor torque, $T_{\mathrm{a}}$, is as follows,

$$
T_{\mathrm{a}}(t)=\frac{1}{2 \omega_{\mathrm{r}}(t)} \rho A V_{\mathrm{r}}^{3} C_{\mathrm{p}}(\lambda(t), \beta(t)), \lambda(t)=\frac{\omega_{\mathrm{r}} R}{V_{\mathrm{r}}},(1)
$$

where $\rho$ is air density, $A$ is swept area, $C_{\mathrm{p}}$ is power coefficient, $\beta$ is blade pitch angle, $\lambda$ is tip speed ratio, $R$ is blade length and $V_{\mathrm{r}}$ is the wind speed at the rotor plane. The nonlinear mapping from the tip speed ratio and the pitch angle to power coefficient is shown in Fig. 2 [13]. 


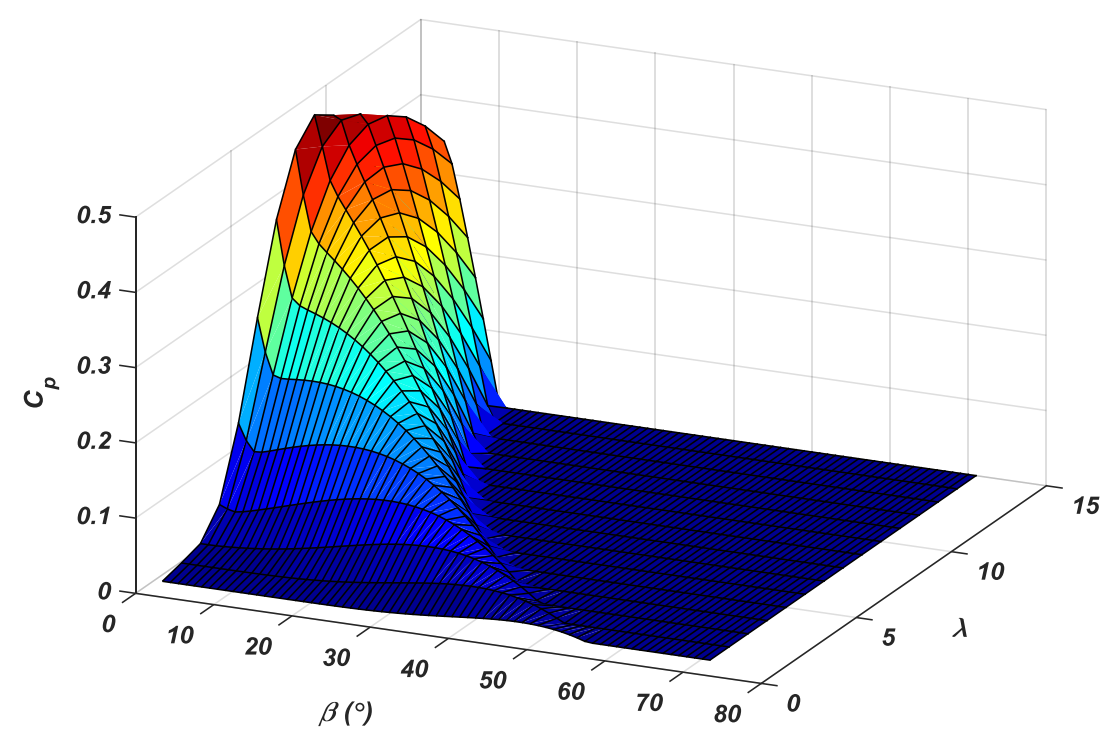

Fig. 2 Power coefficient surface [13]

The power coefficient is modelled as [36],

$$
C_{\mathrm{p}}(\lambda, \beta)=C_{1}\left(\frac{C_{2}}{\lambda_{i}}-C_{3}-C_{4}\right) \mathrm{e}^{\frac{-C_{5}}{\lambda_{i}}}+C_{6} \lambda, \frac{1}{\lambda_{i}}=\frac{1}{\lambda+0.08 \beta}-\frac{0.035}{\beta^{3}+1},(2)
$$

where the constant coefficients in Eq. (2) are $C_{1}=0.5176, C_{2}=116, C_{3}=0.4, C_{4}=5, C_{5}=21$ and $C_{6}=0.0068$. The resulting surface of Eq. (2) is shown in Fig. 2.

The transferred wind power to the rotor can be written as

$$
P_{\mathrm{w}}=0.5 \rho A V_{\mathrm{r}}^{3}, P_{\mathrm{a}}=P_{\mathrm{w}} C_{\mathrm{p}},(3)
$$

where $P_{\mathrm{w}}$ is the available power in wind and $P_{\mathrm{a}}$ is the extracted power into the wind turbine. Analysis of the power coefficient curve and the equation shows that the maximum $C_{\mathrm{p}}$ is 0.48 that occurs at $\beta=0^{\circ}$ and $\lambda=8.1$.

\subsection{Drivetrain model}

The drivetrain transfers the torque and power captured at the rotor plane to the electrical generator. The drivetrain torsional rotation behaviour can be modelled as a two-degree of freedom inertia model including the low speed rotor shaft with inertia $J_{\mathrm{r}}$, and high speed generator shaft with inertia $J_{\mathrm{g}}$, as shown in Fig. 3 .

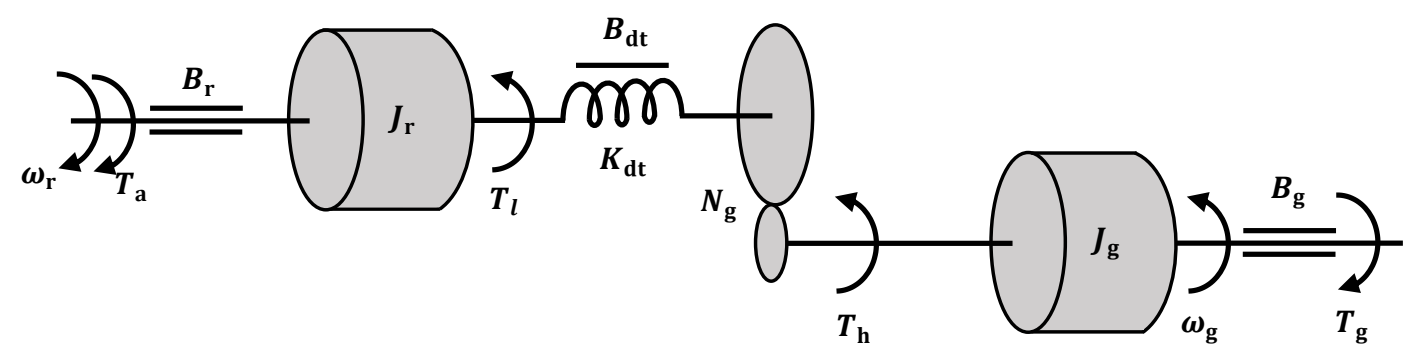

Fig. 3 Drivetrain rotational model 
The gear train increases the shaft speed by the speed ratio_ $N_{\mathrm{g}}$, which when combined with torsion stiffness, $K_{\mathrm{dt}}$, and torsional damping, $B_{\mathrm{dt}}$, results in a torsion angle of twist of the main shaft of $\theta_{\Delta}$. The drivetrain efficiency is $\eta_{\mathrm{dt}}$ and the resulting torque on the generator shaft is $T_{\mathrm{g}}$ rotating at the generator shaft speed $\omega_{\mathrm{g}} . B_{\mathrm{r}}$ and $B_{\mathrm{g}}$ are angular velocity viscous friction components of the rotor and generator shafts, respectively. The dynamics of the rotor shaft is as follows:

$$
J_{\mathrm{r}} \dot{\omega}_{\mathrm{r}}(t)=T_{\mathrm{a}}(t)-B_{\mathrm{r}} \omega_{\mathrm{r}}(t)-T_{1},
$$

where $T_{1}$ is load torque acting on rotor shaft. The dynamics of the generator shaft is as follows:

$$
J_{\mathrm{g}} \dot{\omega}_{\mathrm{g}}(t)=T_{\mathrm{h}}-B_{\mathrm{g}} \omega_{\mathrm{g}}(t)-T_{\mathrm{g}}(t),
$$

where $T_{\mathrm{h}}$ represents the exciting torque acting on the generator shaft. On the other hand, $T_{\mathrm{h}}=\eta_{\mathrm{dt}} T_{1} / N_{\mathrm{g}}$ and a torsion spring and a friction coefficient model the drivetrain torsional response is as follows:

$$
T_{1}=K_{\mathrm{dt}} \theta_{\Delta}(t)+B_{\mathrm{dt}} \dot{\theta}_{\Delta}(t) .
$$

Accordingly, the resulting simplified drivetrain equations of motion can be written as,

$$
\begin{gathered}
J_{\mathrm{r}} \dot{\omega}_{\mathrm{r}}(t)=T_{\mathrm{a}}(t)-K_{\mathrm{dt}} \theta_{\Delta}(t)-\left(B_{\mathrm{r}}+B_{\mathrm{dt}}\right) \omega_{\mathrm{r}}(t)+\frac{B_{\mathrm{dt}}}{N_{\mathrm{g}}} \omega_{\mathrm{g}}(t) \\
J_{\mathrm{g}} \dot{\omega}_{\mathrm{g}}(t)=\frac{\eta_{\mathrm{dt}} K_{\mathrm{dt}}}{N_{\mathrm{g}}} \theta_{\Delta}(t)+\frac{\eta_{\mathrm{dt}} B_{\mathrm{dt}}}{N_{\mathrm{g}}} \omega_{\mathrm{r}}(t)-\left(B_{\mathrm{g}}+\frac{\eta_{\mathrm{dt}} B_{\mathrm{dt}}}{N_{\mathrm{g}}^{2}}\right) \omega_{\mathrm{g}}(t)-T_{\mathrm{g}}(t), \dot{\theta}_{\Delta}(t)=\omega_{\mathrm{r}}(t)-\frac{1}{N_{\mathrm{g}}} \omega_{\mathrm{g}}(t) .
\end{gathered}
$$

\subsection{Pitch system model}

The pitch hydraulic mechanism that is responsible to change the pitch angle of blades to the reference value of pitch angle, $\beta_{\text {ref }}$, which is commanded from controller by a torque $T_{\beta}$, is modelled as a second order system with communication delay, $t_{\mathrm{d}}$, as the following:

$$
J_{\beta} \ddot{\beta}(t)+C_{\beta} \dot{\beta}(t)+K_{\beta} \beta(t)=T_{\beta}\left(t-t_{\mathrm{d}}\right),(5)
$$

where $J_{\beta}, C_{\beta}$ and $K_{\beta}$ represent inertia, damping and spring coefficients of the pitch actuator, respectively. It should be noted that the pitch actuator has both a limited slew rate and a limited operational area.

\subsection{Generator and converter models}

The kinetic energy of the generator shaft is converted to electrical energy via the electromagnetic generator and to enable variable-speed operation, currents in the generator are controlled using a built-in power electronic converter in the generator interfacing with the grid to control the generator currents. The generator torque, $T_{\mathrm{g}}(t)$, is controlled by the speed controller providing the reference torque, $T_{\mathrm{g}, \text { ref }}$. This tracking dynamic element can be modelled as a first order system with time constant $\tau_{\mathrm{g}}$ and communication delay $t_{\mathrm{g}, \mathrm{d}}$ as,

$$
\dot{T}_{\mathrm{g}}(t)=-\frac{1}{\tau_{\mathrm{g}}} T_{\mathrm{g}}(t)+\frac{1}{\tau_{\mathrm{g}}} T_{\mathrm{g}, \text { ref }}\left(t-t_{\mathrm{g}, \mathrm{d}}\right) .
$$

The wind turbine electrical systems and their controllers respond much faster than the reference controller, so the electrical produced power, $P_{\mathrm{g}}(t)$, can be approximated by a static relation including the efficiency of the generator, $\eta_{\mathrm{g}}$ as 


$$
P_{\mathrm{g}}(t)=\eta_{\mathrm{g}} \omega_{\mathrm{g}}(t) T_{\mathrm{g}}(t) \cdot(7)
$$

It should be noted that in the generator subsystem a minimum load, a maximum load, and a slew rate for the load torque, are considered.

\subsection{Modelling assumptions}

In summary, the following assumptions are made in implementing the nonlinear model of the wind turbine in this research [37,38]:

- Power coefficient is approximated by an empirical equation;

- Drivetrain is modelled as a two-degree of freedom rotating system;

- The oscillations of the tower and blades are ignored;

- The yaw mechanism is ignored and the wind is assumed to always be perpendicular to the rotor plane;

- Wind speed fluctuations over the area of the rotor plane are neglected;

- Pitch actuator and generators are modelled as second and first order systems, respectively, with limited operational range and change rate, for more realistic models with time constant and communication delay;

- All blades are pitched identically and have same pitch actuator dynamic behaviour.

\subsection{Assembled model}

The block diagram of the resulting wind turbine model is shown in Fig. 4, where the reference signals for the pitch angle and generator load torque, are generated from the controller. The wind speed, pitch angle and rotor speed in the aerodynamic subsystem provide the aerodynamic torque, which is fed to the drivetrain and generator torque, as well. The electrical power is produced in the generator utilizing the generator speed from the drivetrain and generator torque.

The available measurements in the wind turbines are the generator torque, pitch angle, generator speed, rotor speed and wind speed. Additionally, the output power is evaluated as the product of the measurements of the generator speed and generator torque. Finally, to make the model more realistic, noise was added to the measurement sensors which are used in proposed controller. The noise contents are white noise with Gaussian probability distribution function as:

$\varepsilon_{\omega_{\mathrm{r}}} \square N\left(0,0.025^{2}\right), \varepsilon_{V_{\mathrm{w}}} \square N\left(0,0.5^{2}\right)$ and $\varepsilon_{\beta} \square N\left(0,0.2^{2}\right)$, where $\varepsilon_{i}$ is noise which is added to variable $i$, and $N\left(a, b^{2}\right)$ represents a Gaussian distribution with mean $a$ and standard deviation $b$ [39].

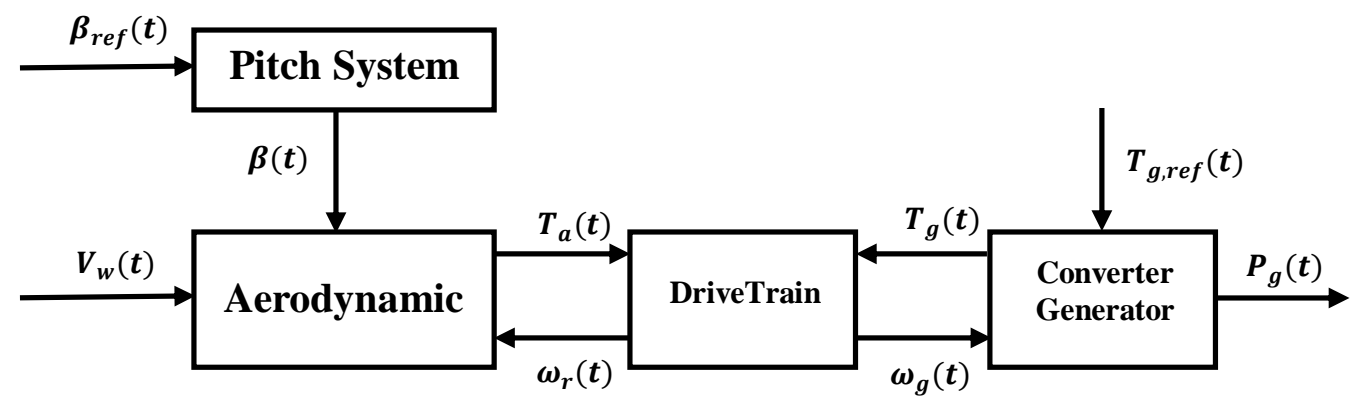

Fig. 4 Wind turbine model at system level

\subsection{Nonlinear state space representation}

This section describes the state space nonlinear model of the wind turbine that is used in the proposed controller. The key point is that the subsystem governing equations should be transferred 
to the rotor shaft to deal with only one equation. The complete equation derived for the system model is presented in Appendix A. Accordingly, by taking $x=\left[\int \dot{\theta}_{r} \mathrm{~d} t, \beta\right]^{\mathrm{T}}$ as the state vector, the model of the wind turbine system can be written in compact form as,

$$
\boldsymbol{H} \ddot{\boldsymbol{x}}+\boldsymbol{g}=\boldsymbol{\tau},(8)
$$

where $\boldsymbol{H} \in \square^{2 \times 2}$ is the lumped inertia matrix, $\boldsymbol{g} \in \square^{2}$ denotes the nonlinearities of the wind turbine, $\tau \in \square^{2}$ is the generator and the pitch actuator control input torques, and can be derived as,

$$
\boldsymbol{H}=\left[\begin{array}{cc}
\left(J_{\mathrm{r}}+\frac{N_{\mathrm{g}}^{2}}{\eta_{\mathrm{dt}}} J_{\mathrm{g}}\right) & 0 \\
0 & J_{\beta}
\end{array}\right], \boldsymbol{g}=\left[\begin{array}{c}
-T_{\mathrm{a}}+\left(B_{\mathrm{r}}+\frac{N_{\mathrm{g}}^{2}}{\eta_{\mathrm{dt}}} B_{\mathrm{g}}\right) \dot{\theta}_{\mathrm{r}} \\
C_{\beta} \dot{\beta}(t)+K_{\beta} \beta(t)
\end{array}\right], \boldsymbol{\tau}=\left[\begin{array}{c}
\frac{-N_{\mathrm{g}}}{\eta_{\mathrm{dt}}} \int\left(-\frac{1}{\tau_{\mathrm{g}}} T_{\mathrm{g}}(t)+\frac{1}{\tau_{\mathrm{g}}} T_{\mathrm{g}, \text { ref }}\left(t-t_{\mathrm{g}, \mathrm{d}}\right)\right) \mathrm{d} t \\
T_{\beta}\left(t-t_{\mathrm{d}}\right)
\end{array}\right]
$$

It should be noted that in practical applications, the real outputs of the controller are $T_{\mathrm{g}, \mathrm{ref}}$ and $T_{\beta}$ and other parameters in $\tau$ can be used to represent the actuator dynamics.

\section{Control strategy}

\subsection{Background on control of partial load operation}

In partial load region, where this research is concentrated, to produce as much power as possible, the maximum point on the power coefficient curve should always be reached. The maximum value of the power coefficient is 0.48 which occurs at $\beta=0^{\circ}$ and $\lambda=8.1$. The variation in wind speed only effects the tip speed ratio, $\lambda$. Thus, the pitch angle is fixed at the optimal value of $\beta=0^{\circ}$. On the other hand, being able to keep the tip speed ratio at 8.1 depends on the wind speed as well as the rotor speed. The wind speed is not controllable, so the rotor speed should be controlled. This aim can be achieved by controlling the generator torque to modify the generator speed and, consequently, the rotor speed.

\subsection{Faults in wind turbine}

The wind turbines, being large and complex mechanical and electrical systems, which operate in harsh environments with high wind speeds and storms and having considerable mechanical vibrations, will always be affected by mechanical and electrical faults which reduce the turbine efficiency and, in some extreme cases, lead to system failure and structural damage [39,40].

Faults are considered as system abnormalities that deviate the system from its normal operation. So, without loss of generality, the best procedure for managing faults that lead to uncontrollable system modes and structural damage, is to shut down the system and proceed with the required maintenance. However, other moderate faults can be managed and controlled passively or actively by correct fault diagnosis and appropriate controller algorithms [41]. In active fault tolerant control, firstly, the fault is going to be detected and then, the location of the detected fault will be isolated. Additionally, via fault identification, the size and type of fault will be determined, Finally, feeding all of this information, to a controller, either a nominal controller or a new one which is switched into the control procedure, the effect of the fault will be removed from the final system [7]. In noisy, uncertain dynamic models with some unavailable models and parameters, e.g., wind turbines, it is a rigorous task to model the system accurately and to deploy model-based fault detection and identify its behaviour. Additionally, in complex systems, different fault sources may have similar final effects on the system. On the other hand, the use of different controllers to be used in faulty situations will increase the cost which is in contrast to the fault tolerant control of systems which aims at keeping the cost at a reasonable level [14]. So, utilizing the passive fault tolerant control concept, the nominal controller is designed such that the final system is robust towards some types of faults which are considered in the control design procedure. Indeed, in passive fault tolerant control the need for fault detection, isolation, identification and reconfiguring of the nominal controller, will be eliminated [27]. Accordingly, in this paper one of 
the most likely faults in wind turbines, which is the actuator fault [12,27], is considered in the controller design. Firstly, faults are considered on the blade pitch actuator that creates torque to rotate the blade to the desired pitch angle, and then secondly, on the generator torque actuator which applies the electromagnetic torque onto the generator shaft to change the rotor speed to track the optimal power coefficient.

The integrated dynamic model of the wind turbine given in Eq. (8), exposed with the fault and disturbance can be written as,

$$
H \ddot{x}+g=\tau+f+d,(9)
$$

where $\boldsymbol{x}=\left[x_{1}, x_{2}\right]^{\mathrm{T}} \in \square^{2}$ denotes the state vector, $\boldsymbol{d}(\bullet) \in \square^{2}$ represents an external disturbance on the wind turbine system considered to be bounded by $\|\boldsymbol{d}\|<\bar{d}$ where $\bar{d}$ is a known finite number which can represent any un-modelled dynamic mode that may affect the system, and $\boldsymbol{f}(t) \in \square^{2}$ is the actuator fault which can be seen as any external torque which is applied onto the generator torque and pitch actuators, other than the ones which are produced by the controller. These faults can be due to high air density, pump wear, hydraulic leakage and internal controller errors in actuators [39].

Property 1: It is assumed that the lumped inertia matrix, $\boldsymbol{H}$, is a known symmetric and positive-definite matrix.

Assumption 1: It is assumed that the fault $\boldsymbol{f}(t)$ exerted on the actuators, is uniformly bounded, i.e., there exists an unknown constant $\overline{\boldsymbol{f}} \in \square^{+}$, such that $\|\boldsymbol{f}(t)\|<\overline{\boldsymbol{f}}, \forall t \in[0, \infty)$. Note that in reality, the exerted fault $f(t)$ is finite and thus it is assumed that it is bounded by an unknown constant $[27,42]$.

\subsection{Problem formulation}

In this paper, the variable-speed variable-pitch wind turbine tracking problem in partial load operation, is formulated to be solved as:

Consider the given smooth desired trajectory $\boldsymbol{x}_{\mathrm{d}}(t)=\left[x_{\mathrm{d} 1}, x_{\mathrm{d} 2}\right]^{\mathrm{T}}$, for the wind turbine dynamics given by Eq. (9), find the generator and the pitch actuator input torques $\tau$ such that the wind turbine states $\boldsymbol{x}=\left[x_{1}, x_{2}\right]^{\mathrm{T}}$ track a given desired trajectory $\boldsymbol{x}_{\mathrm{d}}$ as closely as possible, i.e., $\lim _{t \rightarrow \infty}\left|x_{i}(t)-x_{\mathrm{d} i}(t)\right|=\delta_{i}$ for $i=1,2$ with $\delta_{i}$ being small positive constants, meanwhile the boundedness of the closed-loop system is ensured.

Remark: This paper aims to maximise the aerodynamic power extracted from the wind, by tracking the optimal values of desired states, i.e., the desired rotor speed, $\omega_{\mathrm{rd}}(t)$, and blade pitch angle, $\beta_{\mathrm{d}}(t)$.

\subsection{Preliminaries}

\subsubsection{Neural network}

In the literature on adaptive control of nonlinear systems, due to their approximation property and the learning capability, neural networks are extensively used for approximation of unknown nonlinearities. In this paper, the radial basis function neural networks (RBFNN) as a class of linearly parameterized neural networks are employed to approximate a smooth and continuous function $f(\boldsymbol{Z}): \square^{q} \rightarrow \square$ over a compact set $\boldsymbol{\Omega}_{\boldsymbol{Z}} \subset \square^{q}$ as [43-45]

$$
f(\boldsymbol{Z})=\boldsymbol{\theta}^{* \mathrm{~T}} \boldsymbol{h}(\boldsymbol{Z})+\varepsilon,(10)
$$

where $\boldsymbol{Z}=\left[z_{1}, z_{2}, \ldots, z_{q}\right]^{\mathrm{T}} \in \mathbf{\Omega}_{\boldsymbol{Z}}$ is the neural network input vector, $\boldsymbol{\theta}^{*} \in \square^{s}$ ( $s>1$ is the neural network node number) is an unknown ideal constant weight vector, $\boldsymbol{h}(\boldsymbol{Z})=\left[h_{1}(\boldsymbol{Z}), h_{1}(\boldsymbol{Z}), \ldots, h_{s}(\boldsymbol{Z})\right]^{\mathrm{T}} \in \square^{s}$ is a basis function vector, $\varepsilon \in \square$ represents the unknown 
approximation errors under the ideal neural network weight and can be assumed to be bounded as $|\varepsilon| \leq \bar{\varepsilon}$ with $\bar{\varepsilon}>0$ being an unknown constant. In this study, $h_{i}(\boldsymbol{Z})$ is chosen as a Gaussian function for $i=1,2, \ldots, s$ and can be expressed as

$$
h_{i}(\boldsymbol{Z})=\exp \left[\frac{-\left(\boldsymbol{Z}-\boldsymbol{\vartheta}_{i}\right)^{\mathrm{T}}\left(\boldsymbol{Z}-\boldsymbol{\vartheta}_{i}\right)}{\varphi_{i}^{2}}\right],
$$

where $\varphi_{i}$ is the width of the Gaussian function, and $\vartheta_{i}=\left[\vartheta_{i 1}, \vartheta_{i 2}, \ldots, \vartheta_{i q}\right]^{\mathrm{T}}$ is the center for the $i$ th input element of the neural network. The optimal weight value $\boldsymbol{\theta}^{*}$, is expressed as

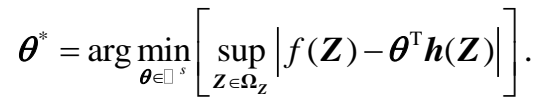

\subsubsection{Technical lemmas}

Lemma 1 [43]: For bounded initial conditions, if there exists a positive definite and $C^{1}$ continuous Lyapunov function $V(\boldsymbol{x})$ satisfying $a_{1}(\|\boldsymbol{x}\|) \leq V(\boldsymbol{x}) \leq a_{2}(\|\boldsymbol{x}\|)$, such that $\dot{V} \leq-b_{1} V(\boldsymbol{x})+b_{2}$ , where $b_{1}$ and $b_{2}$ are positive constants and $a_{1}, a_{2}: \square^{n} \rightarrow \square$ are class $K$ functions, then the solution $\boldsymbol{x}(t)$ is uniformly bounded.

Lemma 2 [46]: For any constant $\eta>0$ and $\Psi \in \square$, the following inequality holds,

$$
0 \leq|\Psi|-\Psi \tanh \left(\frac{\Psi}{\eta}\right) \leq k_{\mathrm{p}} \eta,
$$

where $k_{\mathrm{p}}$ is a constant satisfying $k_{\mathrm{p}}=\mathrm{e}^{-\left(k_{\mathrm{p}}+1\right)}$, i.e., $k_{\mathrm{p}}=0.2785$ and $|\Psi|$ is the absolute value of $\Psi$. From this point onwards, for simplifying notation, it is omitted the state and time dependence of the system, provided no confusion would arise.

\section{Control design}

\subsection{Known wind turbine dynamics}

In case that the wind turbine dynamics, $\boldsymbol{H}, \boldsymbol{g}$, actuator fault $\boldsymbol{f}$ and disturbance $\boldsymbol{d}$ are all known, the model-based control can be designed.

Let $x_{1}=\int \omega_{\mathrm{r}}(q) \mathrm{d} q$ and $x_{2}=\beta$, and define the tracking error variables as $e_{1}=\omega_{\mathrm{rd}}-\omega_{\mathrm{r}}$, and $e_{2}=\beta_{\mathrm{d}}-\beta$ where $\omega_{\mathrm{rd}} \in \square^{+}$and $\beta_{\mathrm{d}} \in \square$ are the desired rotor speed and blade pitch angle, respectively. Further define the filtered tracking error $z \in \square$ as $z=\dot{e}_{2}+\gamma e_{2}$ where $\gamma \in \square^{+}$is a constant control gain; the wind turbine dynamic model given by Eq. (8) can be expressed as

$$
\dot{\boldsymbol{\zeta}}=\boldsymbol{H}^{-1}\left(\boldsymbol{H} \ddot{x_{\mathrm{d}}}-\boldsymbol{H} \ddot{\boldsymbol{x}}+\boldsymbol{\Lambda}\right)=\boldsymbol{H}^{-1}\left(\boldsymbol{H} \ddot{\boldsymbol{x}}_{\mathrm{d}}-\tau-\boldsymbol{f}-\boldsymbol{d}+\boldsymbol{g}+\boldsymbol{\Lambda}\right),(14)
$$

where $\boldsymbol{\zeta}=\left[e_{1}, z\right]^{\mathrm{T}} \in \square^{2}$ is the composite error signal, and $\boldsymbol{\Lambda}=\boldsymbol{H}\left[\begin{array}{c}0 \\ \gamma \dot{e}_{2}\end{array}\right]$.

Theorem 1: For the wind turbine dynamic described by Eq. (9) under Property 1, and proposed control

$$
\tau=\boldsymbol{H} \ddot{\boldsymbol{x}}_{\mathrm{d}}+\boldsymbol{\Lambda}+\boldsymbol{k}_{1} \zeta+\tau_{k},
$$

where $\tau_{k}$ is a part of controller for nonlinearity, disturbance and fault, as

$$
\tau_{k}=\boldsymbol{f}+\boldsymbol{d}-\boldsymbol{g},(16)
$$


and $\boldsymbol{k}_{1}=\boldsymbol{k}_{1}^{\mathrm{T}}>0$ is a $2 \times 2$ control gain matrix, then the closed-loop system is asymptotically stable.

\section{Proof: See Appendix B.}

\subsection{Uncertain wind turbine dynamics}

Typically, in practical applications, wind turbine nonlinear uncertainties in dynamics $g(\bullet)$, actuator fault $f(\bullet)$ and disturbances $\boldsymbol{d}(\bullet)$ are unknown. Accordingly, the control $\tau_{k}$ in Eq. (16) cannot be realized in practice. To overcome that difficulty, the RBFNN approach is developed to approximate uncertainties. Accordingly, the control $\tau_{k}$ can be modified as

$$
\boldsymbol{\tau}_{\boldsymbol{k}}=\hat{\boldsymbol{\theta}}^{\mathrm{T}} \boldsymbol{h}-\hat{\boldsymbol{F}} \tanh \left(\frac{\zeta}{\eta_{1}}\right)+\overline{\boldsymbol{d}} \tanh \left(\frac{\zeta \overline{\boldsymbol{d}}}{\eta_{2}}\right),
$$

and the adaption laws are designed as

$$
\dot{\hat{\boldsymbol{\theta}}}=\boldsymbol{\Gamma}\left(\boldsymbol{\zeta}^{\mathrm{T}} \boldsymbol{h}-\sigma_{\mathrm{C}} \hat{\boldsymbol{\theta}}\right), \dot{\hat{\boldsymbol{F}}}=\boldsymbol{\zeta} \tanh \left(\frac{\boldsymbol{\zeta}}{\eta_{1}}\right)-\sigma_{\mathrm{f}} \hat{\boldsymbol{F}}
$$

where $\hat{\boldsymbol{\theta}}=\left[\hat{\theta}_{1}, \hat{\theta}_{2}, \ldots, \hat{\theta}_{s}\right]^{\mathrm{T}} \in \square^{s}$ is the estimation of ideal weights $\boldsymbol{\theta}^{*} \in \square^{s}$ of the neural network and $\Gamma=\Gamma^{\mathrm{T}}>0$ are the $2 \times 2$ control gain matrices, and $\eta_{1}>0, \eta_{2}>0, \sigma_{\mathrm{C}}>0$ and $\sigma_{\mathrm{f}}>0$ are positive numbers. Note that due to its good approximation ability, neural networks can construct robust and effective frameworks to accommodate system uncertainty [47]. However, the question of how to training the neural network weights remains a challenging issue. Unlike the conventional trainings methods of neural network weights which are mostly based on optimization theory, this paper presents a weight updating law, as in Eq. (18), based on Lyapunov direct method. Employing the neural network explained in Section 4.1, it is defined as $\boldsymbol{g}=\boldsymbol{\theta}^{* \mathrm{~T}} \boldsymbol{h}+\boldsymbol{\varepsilon}$; the input vector $\boldsymbol{Z} \in \square^{2 \times 5}$ is defined as $\boldsymbol{Z}=\left[\boldsymbol{x}^{\mathrm{T}}, \dot{\boldsymbol{x}}^{\mathrm{T}}, \boldsymbol{\zeta}^{\mathrm{T}}, \boldsymbol{x}_{\mathrm{d}}^{\mathrm{T}}, \dot{\boldsymbol{x}}_{\mathrm{d}}^{\mathrm{T}}\right]$ and $\hat{\boldsymbol{F}} \in \square^{2}$ represents the estimations of unknown finite number $\boldsymbol{F} \in \square^{2}$, where $|\overline{\boldsymbol{\varepsilon}}+\overline{\boldsymbol{f}}|<\boldsymbol{F}$. The second terms of the adaption laws in Eq. (18), contains the $\sigma$-modification constants which are designed to improve the system robustness. Note that the control term $\tau_{k}$ in Eq. (17) consists of three parts:

- The first term, $\hat{\boldsymbol{\theta}}^{\mathrm{T}} \boldsymbol{h}$, is designed to estimate the unknown nonlinear uncertainties in the wind turbine dynamics. It uses the RBFNN for the estimation purpose and adapts online using the first adaptive law in Eq. (18).

- The second term, $-\hat{\boldsymbol{F}} \tanh \left(\frac{\zeta}{\eta_{1}}\right)$, is designed for handling completely unknown faults on the actuators. It deals with the system faults with unknown bounds using the Lemma 2, and employing the second adaptive law in Eq. (18). In addition, estimation of $\boldsymbol{F}$, which includes both unknown bounds of faults and the neural network estimation errors, $|\overline{\boldsymbol{\varepsilon}}+\overline{\boldsymbol{f}}|<\boldsymbol{F}$, is used to tackle the difficulties that arise due to the error $\boldsymbol{\varepsilon}$.

- The third term, $\overline{\boldsymbol{d}} \tanh \left(\frac{\zeta \overline{\boldsymbol{d}}}{\eta_{2}}\right)$, is used for handling the unknown disturbances. It designed to employ the Lemma 2 for coping with the uncertainty problem, and since the bound of the disturbances, $\overline{\boldsymbol{d}}$, are known, there is no need to develop a new adaptive law.

Theorem 2: Considering the wind turbine system Eq. (9), under Property 1 and Assumption 1, the control input Eq. (15), and Eq. (16) with the parameter updating law Eq. (17), if the initial conditions are bounded, then the closed-loop system will be uniformly bounded.

Proof: See Appendix C. 


\section{Simulation}

In this section, numerical simulations are performed to evaluate the ability of the proposed controller to control the wind turbine model given by Eq. (9) for two different wind speeds, faults and disturbances. The uncertain wind turbine dynamic model is considered and a RBFNNs with seven nodes on the hidden layer are designed to approximate the model nonlinearities. In addition, disturbances and actuator faults are assumed to be unknown, and modified control given by Eq. (17) with the adaptive laws derived at Eq. (18) is utilized to handle the uncertainties. The necessary parameter values used in the simulation are summarized in Table 1 [17]. Also, the wind speed which is applied on the system is shown in Fig. 5 [15].

Table 1 Wind turbine model values [17]

\begin{tabular}{lc}
\hline Parameter & Value \\
\hline $\boldsymbol{H}, \mathrm{kg} \cdot \mathrm{m}^{2}$ & {$\left[\begin{array}{ll}5 & 0 \\
0 & 5\end{array}\right]$} \\
$R, \mathrm{~m}$ & 2 \\
$A, \mathrm{~m}^{2}$ & 12.6 \\
$\rho, \mathrm{kg} / \mathrm{m}^{3}$ & 1.2 \\
\hline
\end{tabular}

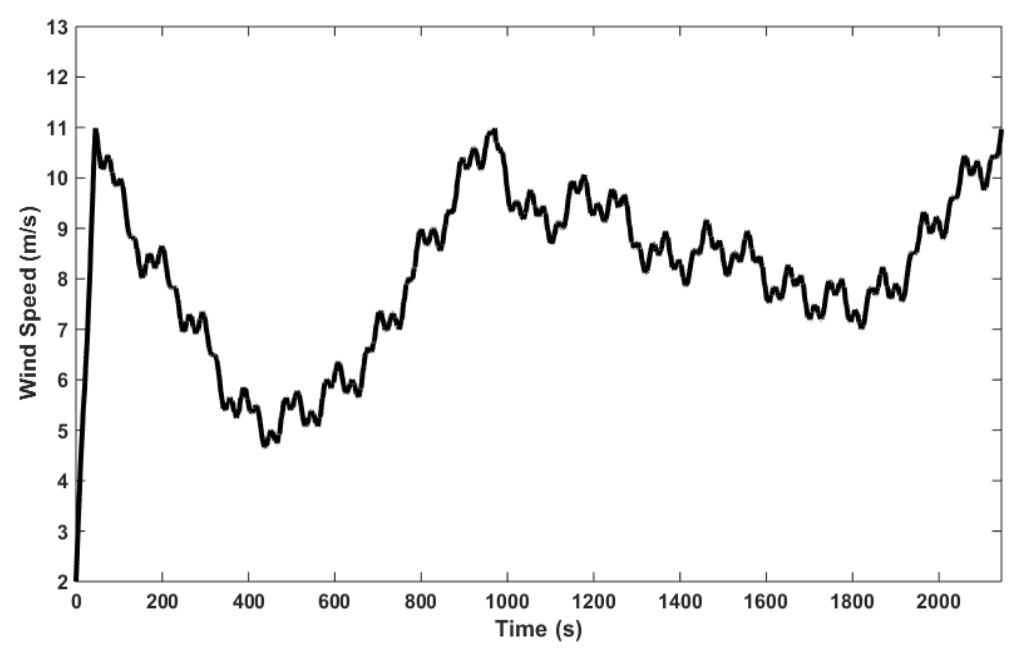

Fig. 5 Wind speed profile.

The desired state variables should be designed such that power coefficient, $C_{\mathrm{p}}$, is always kept at its maximum value, i.e., 0.48 which occurs at $\lambda_{\text {opt }}=8.1$ and $\beta_{\text {opt }}=0^{\circ}$. To hold the tip speed ratio, $\lambda$, at 8.1, the rotor velocity, $\omega_{\mathrm{r}}$, should be varied with respect to the wind speed. It is considered $\omega_{\mathrm{rd}}=\lambda_{\mathrm{opt}} V_{\mathrm{r}} / R$, and consequently the desired value for rotor speed is $\omega_{\mathrm{rd}}=(8.1 / 2) V_{\mathrm{r}}$. Accordingly, the desired value for the first state variable is derived as $\int \dot{\theta}_{\mathrm{rd}} \mathrm{d} t=\int \omega_{\mathrm{rd}} \mathrm{d} t=\int(8.1 / 2) V_{\mathrm{r}} \mathrm{d} t$. On the other hand, the second state variable is the pitch angle which should be kept at zero, i.e., $\beta_{\mathrm{d}}=\beta_{\mathrm{opt}}=0^{\circ}$. These two desired values are used to regulate the response of wind turbine with the proposed controller. Additionally, as mentioned earlier, it is necessary to keep $C_{\mathrm{p}}$ at 0.48 ; so, this can be used to evaluate the correctness of the results. The fault tolerant ability of the controller is verified by applying actuator faults, which are modelled as sinusoidal waveforms as a function of time with amplitudes of $30 \mathrm{~N} \cdot \mathrm{m}$ for both generator and pitch actuators. The above magnitudes of the fault are defined to be applied into the system dynamics Eq. (9) while the actual fault magnitudes are unknown for the uncertain controller in Eq. (17) being derived by the second adaptive laws given by Eq. (18). Also, the disturbances are sinusoidal waveforms as a function of time with amplitudes of $0.1 \mathrm{~N} \cdot \mathrm{m}$ for both generator and pitch actuators. It should be noted that maximum amplitude of disturbances, i.e., $0.1 \mathrm{~N} \cdot \mathrm{m}$, is a known value in the uncertain controller structure. 
Rotor speed, pitch angle, and power coefficient of the system are depicted at Figs. 6-8, respectively. It can be found from Fig. 6 that using the proposed controller, tracking of the desired rotor speed is done successfully despite the wind speed variation, noises and system faults. It is obvious from Fig. 7 that the pitch angle always stays very close to its desired value, i.e., $0^{\circ}$. Finally, Fig. 8 shows that the controller effectively kept the power coefficient very close to its optimal value, i.e., 0.48 , to ensure the wind turbine extracts as much power as possible from the wind.

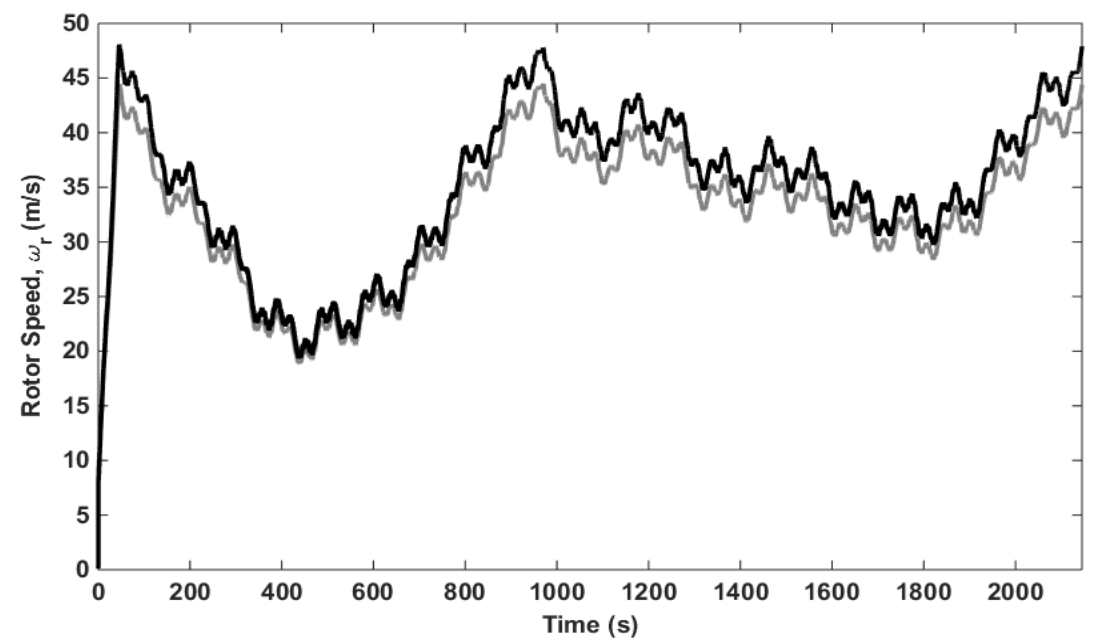

Fig. 6 Rotor speed using proposed controller

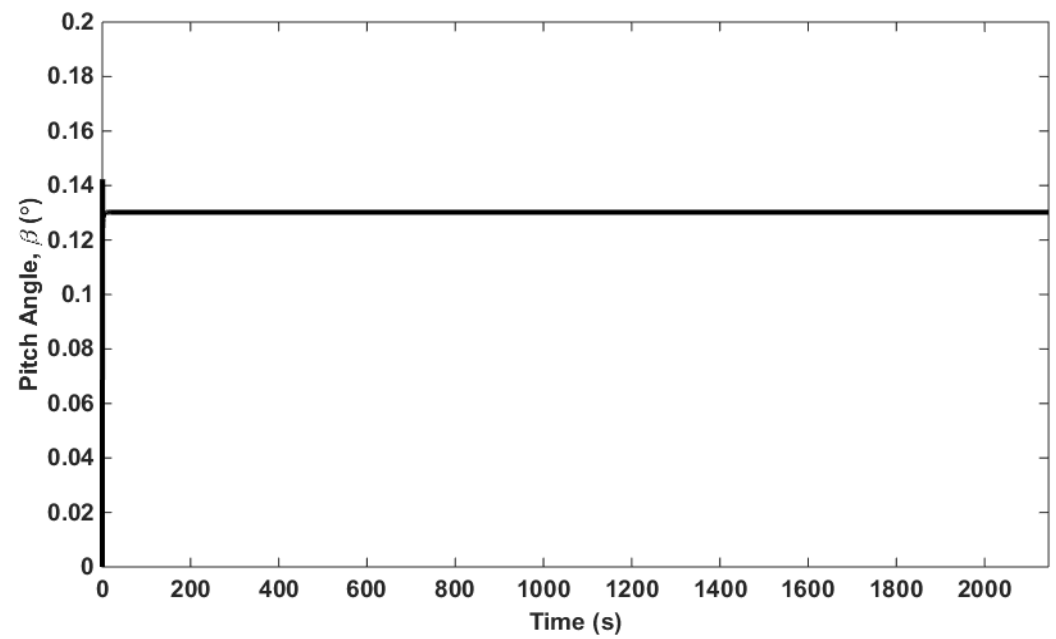

Fig. 7 Pitch angle of wind turbine 


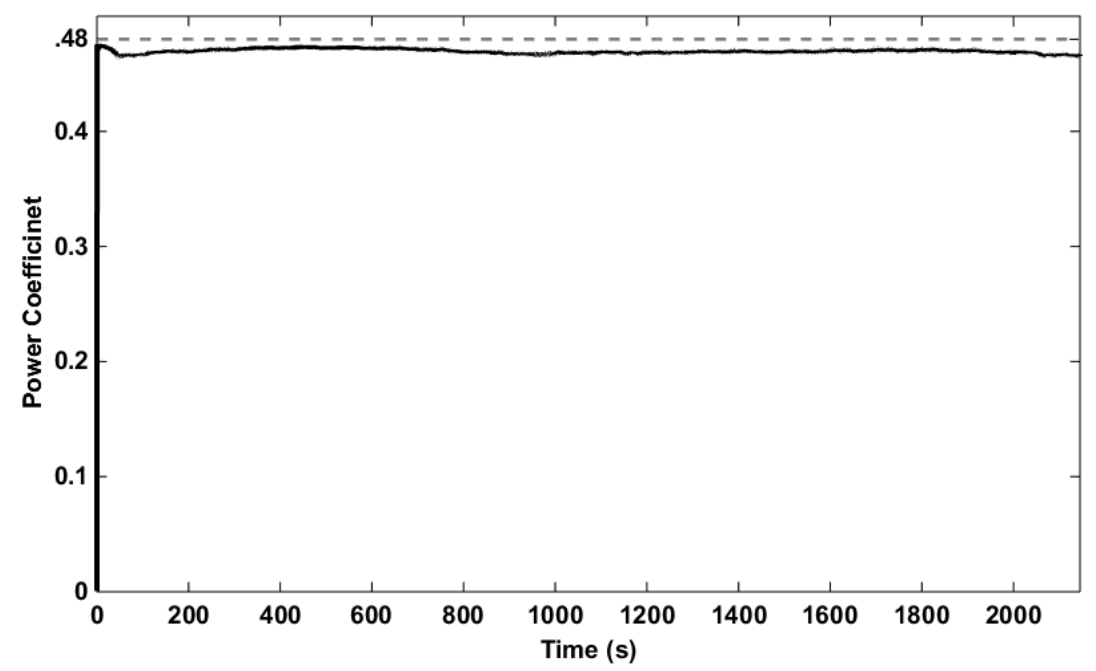

Fig. 8 Power coefficient of wind turbine

Figures 9-12 shows the control efforts. Total generator and pitch actuator torques are shown in Figs. 9 and 10, respectively. Figures 11 and 12 show the generator and pitch torques, which are applied to compensate for the effects of actuator faults, respectively. The figures shows that the magnitudes of the torques are within the practical range [15]. It should be noted that negative values for generator torque are due to the concept that generator torque is applied as a load on the wind turbine. Additionally, the sign of the pitch actuator torque shows the direction that it should be rotated. It is also obvious from the figure that considerable control effort is made to compensate for the effect of the fault on the generator actuator.

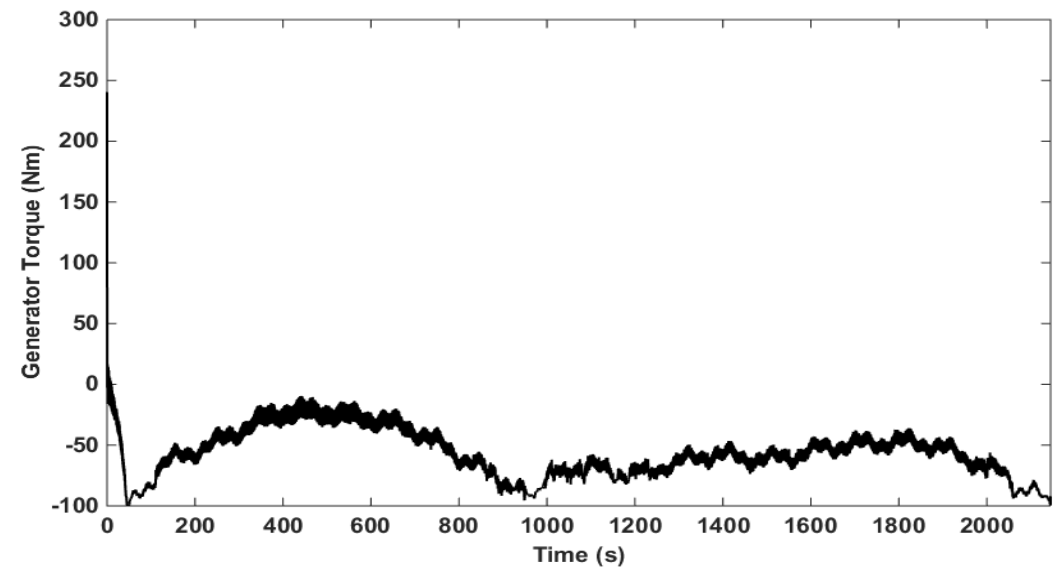

Fig. 9 Total generator actuator torque

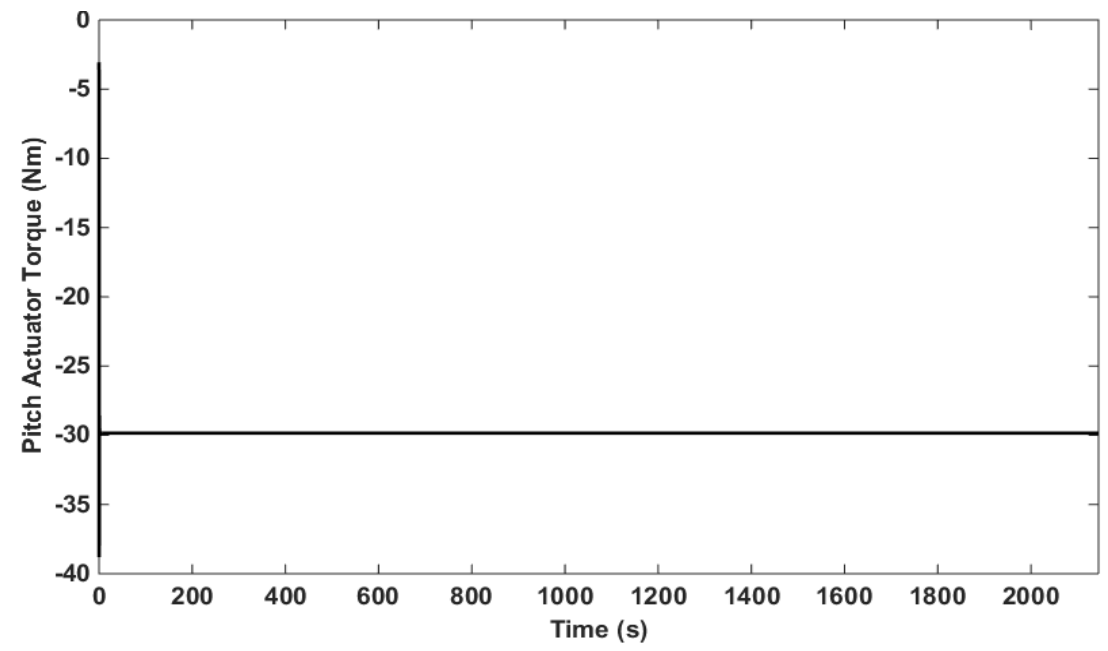


Fig. 10 Total pitch actuator torque

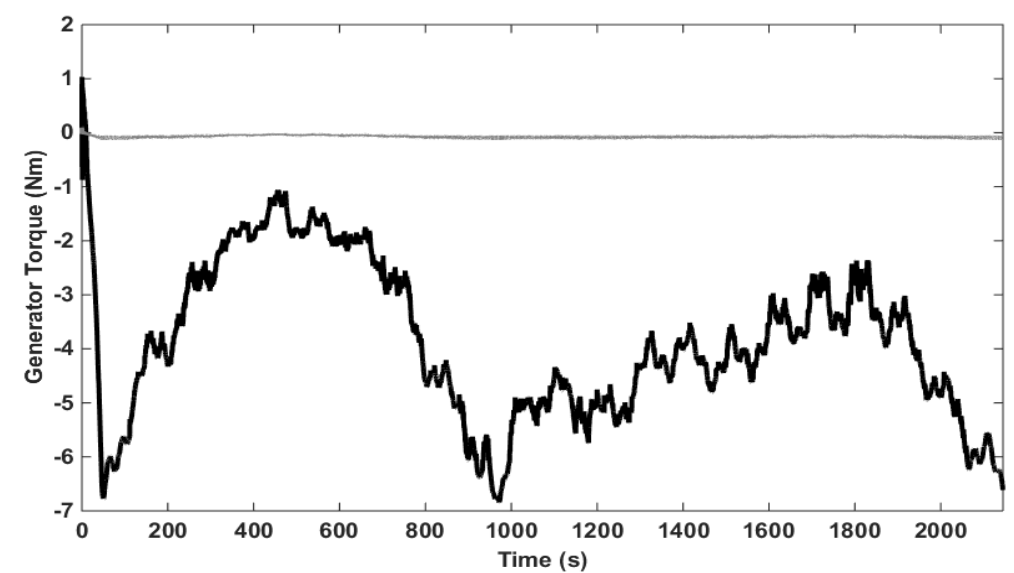

Fig. 11 Applied generator torque due to fault in generator actuator and disturbance

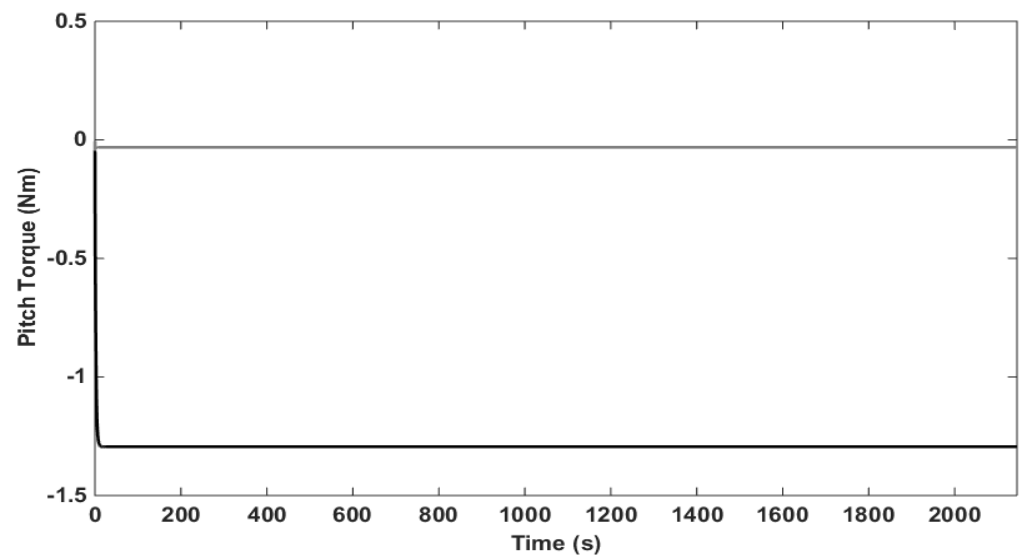

Fig. 12 Applied pitch torque due to fault in pitch actuator and disturbance

Now, to evaluate the proposed controller, a real wind speed, which is measured from a wind farm [9], as shown in Fig. 13, is fed into the wind turbine model. It should be noted that the applied actuator faults are $16 \sin (t / 22)$ for the generator actuator and $20 \sin (t / 60)$ for the pitch actuator. Also, the disturbances are $0.3 \sin (t / 30)$ on the generator actuator and $0.4 \sin (t / 15)$ on the pitch actuator. The rotor speed and desired one are illustrated in Fig. 14. Additionally, the power coefficient is depicted in Fig. 15. It is obvious that the proposed controller is keeping the rotor speed close to the desired one and, as a result, the power coefficient is close to its maximum of one.

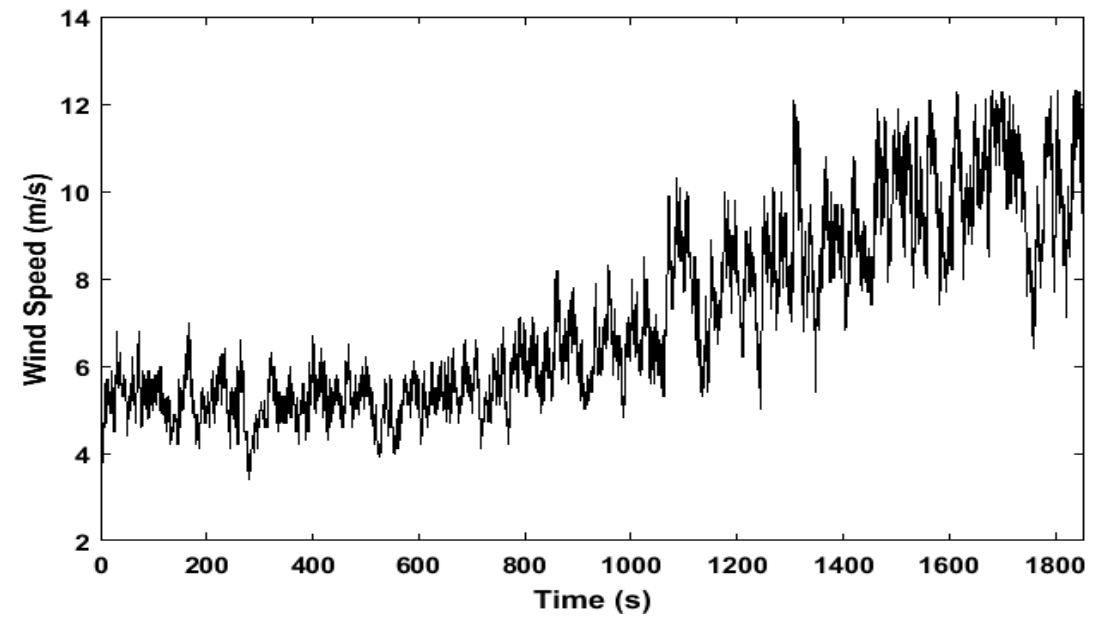

Fig. 13 Real wind speed profile 


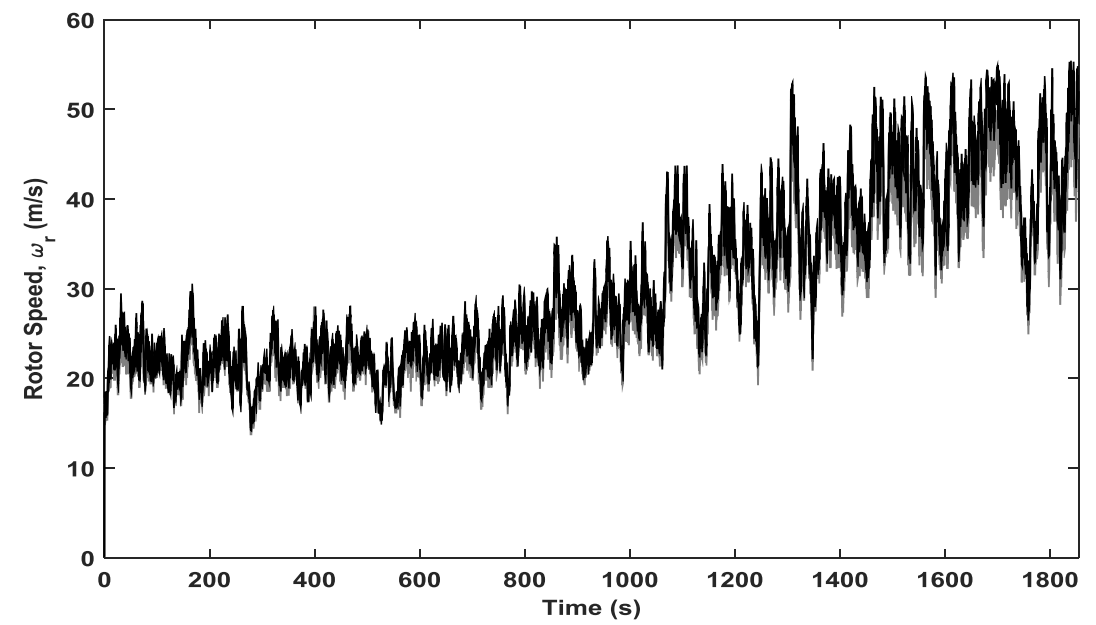

Fig. 14 Rotor speed using proposed controller for real wind speed profile

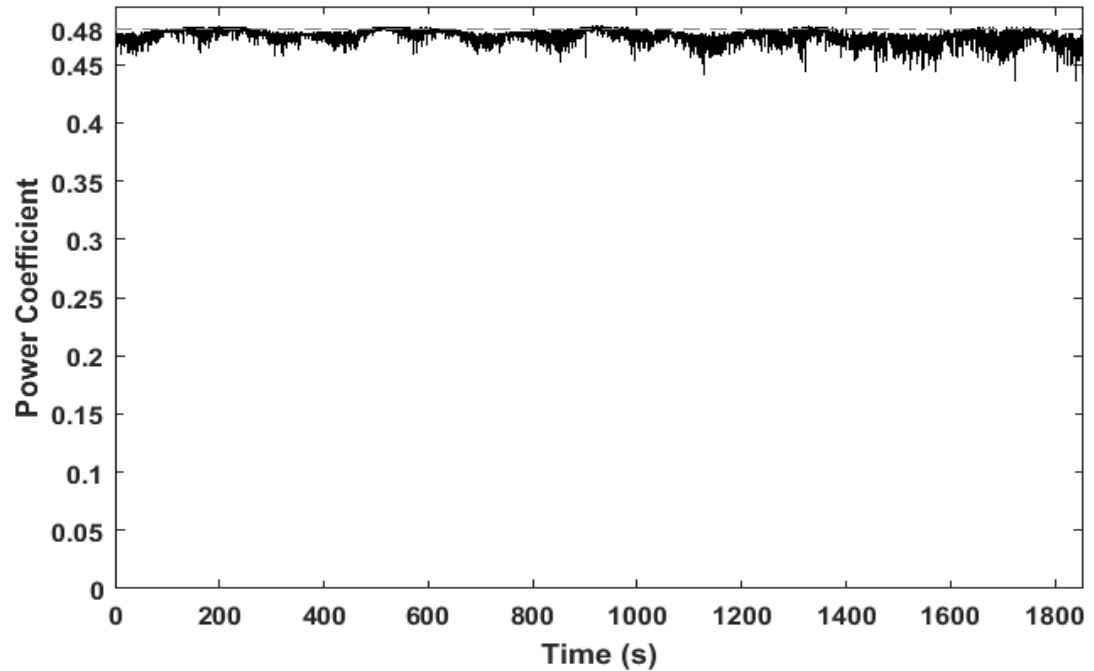

Fig. 15 Power coefficient of wind turbine for real wind speed profile.

\section{Conclusions}

In this paper, nonlinear adaptive FTC has been developed for wind turbine systems. The nonlinear dynamic model has been derived and the desirable variables have been designed to be optimal such that the wind turbine produces the maximum power. Neural networks have been employed and appropriate update laws have been designed to compensate for the system uncertainties and to improve the robustness. Actuator faults on generator and pitch torque actuators have been considered, and the passive characteristic of the proposed controller has been presented to be tolerant against unknown faults. It is proved that under the proposed adaptive FTC scheme, uniform boundedness of the closed-loop wind turbine system is achieved. Numerical simulations have been performed and results showed that the controller, despite the presence of faults and disturbances, is able to track the desired trajectories of rotor speed and pitch angle to maintain wind turbine operation in the optimal operating area. It also showed the capability of the proposed control approach to keep the wind turbine system working at its maximum power coefficient which guarantees the maximum power generation. 


\section{Appendices}

\section{Appendix A: Derivation of nonlinear state space wind turbine model}

The wind turbine nonlinear model is derived by transferring all subsystems equations around the rotor shaft. First, the generator dynamic equation is transferred onto the rotor shaft. Then, it is assumed that the gears are rigid, so that the gear torsion angle is $\theta_{\Delta}=0$ and consequently, $N_{\mathrm{g}} \omega_{\mathrm{r}}=\omega_{\mathrm{g}}$. Accordingly, considering Fig. 2,

$$
\begin{gathered}
J_{\mathrm{r}} \ddot{\theta}_{\mathrm{r}}=T_{\mathrm{a}}-T_{1}-B_{\mathrm{r}} \dot{\theta}_{\mathrm{r}}, J_{\mathrm{g}} \ddot{\theta}_{\mathrm{g}}=T_{\mathrm{h}}-T_{\mathrm{g}}-B_{\mathrm{g}} \dot{\theta}_{\mathrm{g}}, T_{\mathrm{h}}=\eta_{\mathrm{dt}} \frac{T_{\mathrm{l}}}{N_{\mathrm{g}}}, \theta_{\mathrm{g}}=N_{\mathrm{g}} \theta_{\mathrm{r}}, \\
\Rightarrow J_{\mathrm{r}} \ddot{\theta}_{\mathrm{r}}=T_{\mathrm{a}}-\frac{N_{\mathrm{g}} T_{\mathrm{h}}}{\eta_{\mathrm{dt}}}-B_{\mathrm{r}} \dot{\theta}_{\mathrm{r}}, \\
\Rightarrow J_{\mathrm{r}} \ddot{\theta}_{\mathrm{r}}=T_{\mathrm{a}}-\frac{N_{\mathrm{g}}}{\eta_{\mathrm{dt}}}\left(J_{\mathrm{g}} \ddot{\theta}_{\mathrm{g}}+T_{\mathrm{g}}+B_{\mathrm{g}} \dot{\theta}_{\mathrm{g}}\right)-B_{\mathrm{r}} \dot{\theta}_{\mathrm{r}}, \\
\Rightarrow\left(J_{\mathrm{r}}+\frac{N_{\mathrm{g}}^{2}}{\eta_{\mathrm{dt}}} J_{\mathrm{g}}\right) \ddot{\theta}_{\mathrm{r}}+\left(-T_{a}+\left(B_{\mathrm{r}}+\frac{N_{\mathrm{g}}^{2}}{\eta_{\mathrm{dt}}} B_{\mathrm{g}}\right) \dot{\theta}_{\mathrm{r}}\right)=-\frac{N_{\mathrm{g}}}{\eta_{\mathrm{dt}}} T_{\mathrm{g}} .(\mathrm{A} 1)
\end{gathered}
$$

Additionally, the pitch actuator can be formulated as,

$$
J_{\beta} \ddot{\beta}(t)+\left(C_{\beta} \dot{\beta}(t)+K_{\beta} \beta(t)\right)=T_{\beta}\left(t-t_{\mathrm{d}}\right) .
$$

On the other hand, the generator torque actuator which produces the load torque becomes,

$$
T_{\mathrm{g}}(t)=\int\left(-\frac{1}{\tau_{\mathrm{g}}} T_{\mathrm{g}}(t)+\frac{1}{\tau_{\mathrm{g}}} T_{\mathrm{g}, \text { ef }}\left(t-t_{\mathrm{g}, \mathrm{d}}\right)\right) \mathrm{d} t .
$$

Now by taking $\boldsymbol{x}=\left[\int \dot{\theta}_{r} \mathrm{~d} t, \beta\right]^{\mathrm{T}}$ as the state vector the system is as follows.

$$
\boldsymbol{H} \ddot{\boldsymbol{x}}+\boldsymbol{g}=\boldsymbol{\tau},(22)
$$

where,

$$
\boldsymbol{H}=\left[\begin{array}{cc}
J_{\mathrm{r}}+\frac{N_{\mathrm{g}}^{2}}{\eta_{\mathrm{dt}}} J_{\mathrm{g}} & 0 \\
0 & J_{\beta}
\end{array}\right], \boldsymbol{g}=\left[\begin{array}{c}
-T_{\mathrm{a}}+\left(B_{\mathrm{r}}+\frac{N_{\mathrm{g}}^{2}}{\eta_{\mathrm{dt}}} B_{\mathrm{g}}\right) \dot{\theta}_{\mathrm{r}} \\
C_{\beta} \dot{\beta}(t)+K_{\beta} \beta(t)
\end{array}\right], \boldsymbol{\tau}=\left[\begin{array}{c}
-\frac{N_{\mathrm{g}}}{\eta_{\mathrm{dt}}} \int\left(-\frac{1}{\tau_{\mathrm{g}}} T_{\mathrm{g}}(t)+\frac{1}{\tau_{\mathrm{g}}} T_{\mathrm{g}, \text { ref }}\left(t-t_{\mathrm{g}, \mathrm{d}}\right)\right) \mathrm{d} t \\
T_{\beta}\left(t-t_{\mathrm{d}}\right)
\end{array}\right],
$$

where $\tau$ is the controller signal vector.

\section{Appendix B: Proof of Theorem 1}

Choose a non-negative Lyapunov candidate function as,

$$
V=\frac{1}{2} \boldsymbol{\zeta}^{\mathrm{T}} \boldsymbol{H} \boldsymbol{\zeta}
$$

The time derivative of Eq. (23) is given by

$$
\dot{\boldsymbol{V}}=\boldsymbol{\zeta}^{\mathrm{T}} \boldsymbol{H} \dot{\boldsymbol{\zeta}}=\boldsymbol{\zeta}^{\mathrm{T}}\left(\boldsymbol{H} \ddot{\boldsymbol{x}}_{\mathrm{d}}-\boldsymbol{\tau}-\boldsymbol{f}-\boldsymbol{d}+\boldsymbol{g}+\boldsymbol{\Lambda}\right) .
$$

Substituting Eqs. (15) and (16) into Eq. (24) results in 


$$
\dot{V} \leq-k_{1} \zeta^{\mathrm{T}} \zeta \leq 0
$$

Accordingly, considering Property 1, and noting that $\lambda_{\min }(\boldsymbol{H})\|\zeta\|^{2} \leq V \leq \lambda_{\max }(\boldsymbol{H})\|\zeta\|^{2}$ and using the Barbalat lemma [48], asymptotic stability of the wind turbine system is simply drawn.

\section{Appendix C: Proof of Theorem 2}

Choose an augmented non-negative Lyapunov candidate function as

$$
V=\frac{1}{2} \boldsymbol{\zeta}^{\mathrm{T}} \boldsymbol{H} \boldsymbol{\zeta}+\frac{1}{2} \tilde{\boldsymbol{\theta}}^{\mathrm{T}} \boldsymbol{\Gamma}^{-1} \tilde{\boldsymbol{\theta}}+\frac{1}{2} \tilde{\boldsymbol{F}}^{\mathrm{T}} \tilde{\boldsymbol{F}},(26)
$$

where $\tilde{\boldsymbol{\theta}}=\hat{\boldsymbol{\theta}}-\boldsymbol{\theta}^{*}$, and $\|\tilde{\boldsymbol{\theta}}\| \leq \varepsilon_{1}$, and $\tilde{\boldsymbol{F}}=\hat{\boldsymbol{F}}-\boldsymbol{F}$. The time derivative of Eq. (23) is given by

$$
\dot{V}=\boldsymbol{\zeta}^{\mathrm{T}}\left(\boldsymbol{H} \ddot{\boldsymbol{x}}_{\boldsymbol{d}}-\boldsymbol{\tau}-\boldsymbol{f}-\boldsymbol{d}+\boldsymbol{g}+\boldsymbol{\Lambda}\right)+\tilde{\boldsymbol{\theta}}^{\mathrm{T}} \boldsymbol{\Gamma}^{-1} \dot{\hat{\boldsymbol{\theta}}}+\tilde{\boldsymbol{F}} \dot{\hat{\boldsymbol{F}}} .
$$

Using Lemma 2, it can be obtained that

$$
|\zeta| \boldsymbol{F}-\zeta \boldsymbol{F} \tanh \left(\frac{\zeta}{\eta_{1}}\right) \leq k_{p} \boldsymbol{F} \eta_{1}
$$

and

$$
|\zeta| \overline{\boldsymbol{d}}-\zeta \overline{\boldsymbol{d}} \tanh \left(\frac{\zeta \overline{\boldsymbol{d}}}{\eta_{2}}\right) \leq k_{\mathrm{p}} \eta_{2}
$$

In addition, through completion of squares it is obvious that,

$$
-\sigma_{\mathrm{C}} \tilde{\boldsymbol{\theta}}^{\mathrm{T}} \hat{\boldsymbol{\theta}} \leq-\frac{\sigma_{\mathrm{C}}}{2}\|\tilde{\boldsymbol{\theta}}\|^{2}+\frac{\sigma_{\mathrm{C}}}{2}\left\|\boldsymbol{\theta}^{*}\right\|^{2}
$$

where $\sigma_{\mathrm{C}}$ is a positive number and

$$
-\frac{\sigma_{\mathrm{C}}}{2}\|\tilde{\boldsymbol{\theta}}\|^{2} \leq-\frac{1}{2} \frac{\sigma_{\mathrm{C}}}{\lambda_{\max }\left(\boldsymbol{\Gamma}^{-1}\right)} \tilde{\boldsymbol{\theta}}^{\mathrm{T}} \boldsymbol{\Gamma}_{i}^{-1} \tilde{\boldsymbol{\theta}}
$$

Also,

$$
-\sigma_{\mathrm{f}} \tilde{\boldsymbol{F}} \hat{\boldsymbol{F}}=-\sigma_{\mathrm{f}} \tilde{\boldsymbol{F}}(\boldsymbol{F}+\tilde{\boldsymbol{F}}) \leq-\frac{\sigma_{\mathrm{f}}}{2} \tilde{\boldsymbol{F}}^{2}+\frac{\sigma_{\mathrm{f}}}{2} \boldsymbol{F}^{2}
$$

Substituting Eqs. (15) and (17) into Eq. (27) and considering Eqs. (28)-(32), Eq. (27) can be reformed as

$$
\dot{V} \leq k_{1} \zeta^{\mathrm{T}} \boldsymbol{\zeta}-\frac{1}{2} \frac{\sigma_{\mathrm{C}}}{\lambda_{\max }\left(\boldsymbol{\Gamma}^{-1}\right)} \tilde{\boldsymbol{\theta}}^{\mathrm{T}} \boldsymbol{\Gamma}^{-1} \tilde{\boldsymbol{\theta}}-\frac{\sigma_{f}}{2} \tilde{\boldsymbol{F}}^{2}+\frac{\sigma_{\mathrm{C}}}{2}\left\|\boldsymbol{\theta}^{*}\right\|^{2}+\frac{\sigma_{\mathrm{f}}}{2} \boldsymbol{F}^{2}+k_{\mathrm{p}} \boldsymbol{F} \eta_{1}+k_{\mathrm{p}} \eta_{2} \leq-b_{1} V+b_{2},
$$

where $b_{1}=\min \left(\frac{2 \lambda_{\max }\left(\boldsymbol{k}_{1}\right)}{\lambda_{\max }(\boldsymbol{H})}, \min \left(\frac{\sigma_{C}}{\lambda_{\max }\left(\boldsymbol{\Gamma}^{-1}\right)}\right), \min \left(\sigma_{\mathrm{f}}\right)\right)$, and $b_{2}=\frac{\sigma_{\mathrm{C}}}{2}\left\|\boldsymbol{\theta}^{*}\right\|^{2}+\frac{\sigma_{\mathrm{f}}}{2} \boldsymbol{F}^{2}+k_{\mathrm{p}} \boldsymbol{F} \eta_{1}+k_{\mathrm{p}} \eta_{2}$.

Accordingly, using Lemma 1 and choosing the bounded initial condition, the closed-loop system of wind turbine given by Eq. (9) is uniformly bounded.

\section{References}

1. Spudić V, Jelavić M, Baotić M. Supervisory controller for reduction of wind turbine loads in curtailed operation. Control Engineering Practice, 2015, 36: 72-86 doi:10.1016/i.conengprac.2014.11.005

2. Bianchi F D, De Battista H, Mantz R J. Wind Turbine Control Systems: Principles, Modelling and Gain Scheduling Design. London: Springer Science \& Business Media, 2006 
3. Kamal E, Aitouche A, Abbes D. Robust fuzzy scheduler fault tolerant control of wind energy systems subject to sensor and actuator faults. International Journal of Electrical Power \& Energy Systems, 2014, 55: 402-419 doi:10.1016/j.ijepes.2013.09.021

4. Njiri J G, Söffker D. State-of-the-art in wind turbine control: Trends and challenges. Renewable \& Sustainable Energy Reviews, 2016, 60: 377-393 doi:10.1016/j.rser.2016.01.110

5. Yu X, Jiang J. A survey of fault-tolerant controllers based on safety-related issues. Annual Reviews in Control, 2015, 39: 46-57 doi:10.1016/i.arcontrol.2015.03.004

6. Kandukuri S T, Klausen A, Karimi H R, et al. A review of diagnostics and prognostics of low-speed machinery towards wind turbine farm-level health management. Renewable \& Sustainable Energy Reviews, 2016, 53: 697-708 doi:10.1016/j.rser.2015.08.061

7. Gao Z, Cecati C, Ding S X. A survey of fault diagnosis and fault-tolerant techniques-Part I: Fault diagnosis with model-based and signal-based approaches. IEEE Transactions on Industrial Electronics, 2015, 62(6): 3757-3767 doi:10.1109/TIE.2015.2417501

8. Gao Z, Cecati C, Ding S X. A Survey of fault diagnosis and fault-tolerant techniques-Part II: Fault diagnosis with knowledge-based and hybrid/active approaches. IEEE Transactions on Industrial Electronics, 2015, 62(6): 3768-3774 doi:10.1109/TIE.2015.2417501

9. Odgaard P F, Stoustrup J. A benchmark evaluation of fault tolerant wind turbine control concepts. IEEE Transactions on Control Systems Technology, 2015, 23(3): 1221-1228 doi:10.1109/TCST.2014.2361291

10. Vidal Y, Tutivén C, Rodellar J, et al. Fault diagnosis and fault-tolerant control of wind turbines via a discrete time controller with a disturbance compensator. Energies, 2015, 8(5): 4300-4316 doi:10.3390/en8054300

11. Blanke M, Kinnaert M, Lunze J, et al. Diagnosis and Fault-Tolerant Control. 2nd ed. New York: Springer, 2006

12. Odgaard P F, Stoustrup J, Kinnaert M. Fault-tolerant control of wind turbines: A benchmark model. IEEE Transactions on Control Systems Technology, 2013, 21(4): 1168-1182 doi:10.1109/TCST.2013.2259235

13. Habibi H, Koma A Y, Sharifian A. Power and velocity control of wind turbines by adaptive fuzzy controller during full load operation. Iranian Journal of Fuzzy Systems, 2016, 13(3): 35-48

14. Sloth C, Esbensen T, Stoustrup J. Active and passive fault-tolerant LPV control of wind turbines. In: Proceedings of American Control Conference (ACC). 2010, 2010, 4640-4646 doi:10.1109/ACC.2010.5531061

15. Esbensen T, Jensen B, Niss M, et al. Joint power and speed control of wind turbines. Aalborg University, Aalborg, vol. 120,2008

16. Johnson K E, Fingersh L J, Balas M J, et al. Methods for increasing Region 2 power capture on a variable-speed wind turbine. Journal of Solar Energy Engineering, 2004, 126(4): 1092-1100 doi:10.1115/1.1792653

17. Iyasere E, Salah M, Dawson D, et al. Optimum seeking-based nonlinear controller to maximise energy capture in a variable speed wind turbine. IET Control Theory \& Applications, 2012, 6(4): 526-532 doi:10.1049/iet-cta.2010.0689

18. Boukhezzar B, Siguerdidjane H, Hand M M. Nonlinear control of variable-speed wind turbines for generator torque limiting and power optimization. Journal of Solar Energy Engineering, 2006, 128(4): 516-530 doi:10.1115/1.2356496

19. Østergaard K Z, Brath P, Stoustrup J. Estimation of effective wind speed. Journal of Physics: Conference Series, 2007, 75(1): 012082 doi:10.1088/1742-6596/75/1/012082

20. Johnson K E, Pao L Y, Balas M J, et al. Control of variable-speed wind turbines: Standard and adaptive techniques for maximizing energy capture. IEEE Control Systems, 2006, 26(3): 70-81 doi:10.1109/MCS.2006.1636311

21. Li S, Wang H, Tian Y, et al. A RBF neural network based MPPT method for variable speed wind turbine system. IFAC-PapersOnLine, 2015, 48(21): 244-250 doi:10.1016/j.ifacol.2015.09.535

22. Odgaard P F, Stoustrup J. A benchmark evaluation of fault tolerant wind turbine control concepts. IEEE Transactions on Control Systems Technology, 2015, 23(3): 1221-1228 doi:10.1109/TCST.2014.2361291

23. Odgaard P F, Stoustrup J. An evaluation of fault tolerant wind turbine control schemes applied to a benchmark model. In: Proceedings of IEEE Conference on Control Applications (CCA). IEEE, 2014, 1366-1371

24. Odgaard P F, Stoustrup J, Nielsen R, et al. Observer based detection of sensor faults in wind turbines. In: Proceedings of European Wind Energy Conference. 2009, 4421-4430 doi:10.1109/CCA.2010.5611266

25. Tabatabaeipour S M, Odgaard P F, Bak T, et al. Fault detection of wind turbines with uncertain parameters: A setmembership approach. Energies, 2012, 5(12): 2424-2448 doi:10.3390/en5072424

26. Badihi H, Zhang Y, Hong H. Fuzzy gain-scheduled active fault-tolerant control of a wind turbine. Journal of the Franklin Institute, 2014, 351(7): 3677-3706 doi:10.1016/j.jfranklin.2013.05.007

27. Sloth C, Esbensen T, Stoustrup J. Robust and fault-tolerant linear parameter-varying control of wind turbines. Mechatronics, 2011, 21(4): 645-659 doi:10.1016/j.mechatronics.2011.02.001

28. Boukhezzar B, Siguerdidjane H. Comparison between linear and nonlinear control strategies for variable speed wind turbines. Control Engineering Practice, 2010, 18(12): 1357-1368 doi:10.1016/j.conengprac.2010.06.010 
29. Tang C, Guo Y, Jiang J. Nonlinear dual-mode control of variable-speed wind turbines with doubly fed induction generators. IEEE Transactions on Control Systems Technology, 2011, 19(4): 744-756 doi:10.1109/TCST.2010.2053931

30. Boukhezzar B, Siguerdidjane H. Nonlinear control with wind estimation of a DFIG variable speed wind turbine for power capture optimization. Energy Conversion and Management, 2009, 50(4): 885-892 doi:10.1016/j.enconman.2009.01.011

31. Civelek Z, Lüy M, Çam E, et al. Control of pitch angle of wind turbine by fuzzy PID controller. Intelligent Automation \& Soft Computing, 2016, 22(3): 463-471 doi:10.1080/10798587.2015.1095417

32. Van T L, Nguyen T H, Lee D C. Advanced pitch angle control based on fuzzy logic for variable-speed wind turbine systems. IEEE Transactions on Energy Conversion, 2015, 30(2): 578-587 doi:10.1109/TEC.2014.2379293

33. Han B, Zhou L, Yang F, et al. Individual pitch controller based on fuzzy logic control for wind turbine load mitigation. IET Renewable Power Generation, 2016, 10(5): 687-693 doi:10.1049/iet-rpg.2015.0320

34. Medjber A, Guessoum A, Belmili H, et al. New neural network and fuzzy logic controllers to monitor maximum power for wind energy conversion system. Energy, 2016, 106: 137-146 doi:10.1016/j.energy.2016.03.026

35. Assareh E, Biglari M. A novel approach to capture the maximum power from variable speed wind turbines using PI controller, RBF neural network and GSA evolutionary algorithm. Renewable \& Sustainable Energy Reviews, 2015, 51: 1023-1037 doi:10.1016/j.rser.2015.07.034

36. Heier S. Grid Integration of Wind Energy Conversion Systems. New York: John Wiley \& Sons, Inc., 1998

37. Wang H, Pintea A, Christov N, et al. Modelling and recursive power control of horizontal variable speed wind turbines. Journal of Control Engineering and Applied Informatics, 2012, 14(4): 33-41

38. Hand M, Johnson K, Fingersh L, et al. Advanced Control Design and Field Testing for Wind Turbines at the National Renewable Energy Laboratory. National Renewable Energy Laboratory Report, NREL/CP-500-36118. 2004

39. Esbensen T, Sloth C. Fault diagnosis and fault-tolerant control of wind turbines. Dissertation for the Master's Degree. Aalborg: Aalborg University, 2009

40. Hammerum K. A fatigue approach to wind turbine control. Technical University of Denmark, DTU, DK-2800 Kgs. Lyngby, Denmark, 2006

41. Isermann R. Fault-Diagnosis Systems: An Introduction from Fault Detection to Fault Tolerance. New York: Springer Science \& Business Media, 2006

42. Kamal E, Aitouche A. Robust fault tolerant control of DFIG wind energy systems with unknown inputs. Renewable Energy, 2013, 56: 2-15 doi:10.1016/j.renene.2012.10.024

43. Ge S S, Wang C. Adaptive neural control of uncertain MIMO nonlinear systems. IEEE Transactions on Neural Networks, 2004, 15(3): 674-692 doi:10.1109/TNN.2004.826130

44. Yu H, Xie T, Paszczynski S, et al. Advantages of radial basis function networks for dynamic system design. IEEE Transactions on Industrial Electronics, 2011, 58(12): 5438-5450 doi:10.1109/TIE.2011.2164773

45. Liu J. Radial Basis Function (RBF) Neural Network Control for Mechanical Systems: Design, Analysis and Matlab Simulation. New York: Springer Science \& Business Media, 2013

46. Polycarpou M M, Ioannou P A. A robust adaptive nonlinear control design. Automatica, 1996, 32(3): 423-427 doi:10.1016/0005-1098(95)00147-6

47. Rahimi H N, Nazemizadeh M. Dynamic analysis and intelligent control techniques for flexible manipulators: A review. Advanced Robotics, 2013, 28(2): 63-76 doi:10.1080/01691864.2013.839079

48. Slotine J J E, Li W. Applied Nonlinear Control. Englewood Cliffs: Prentice-Hall, 1991 